\title{
Characterization and mitigation of water vapor effects in the measurement of ozone by chemiluminescence with nitric oxide
}

\author{
P. Boylan ${ }^{1, *}$, D. Helmig ${ }^{1}$, and J.-H. Park ${ }^{1, * *}$ \\ ${ }^{1}$ Institute of Arctic and Alpine Research (INSTAAR), University of Colorado, Boulder, USA \\ *now at: Earth Observing Laboratory, NCAR, Boulder, CO, USA \\ **now at: Atmospheric Chemistry Division, NCAR, Boulder, CO, USA
}

Correspondence to: D. Helmig (detlev.helmig@ colorado.edu)

Received: 4 September 2013 - Published in Atmos. Meas. Tech. Discuss.: 29 October 2013

Revised: 10 March 2014 - Accepted: 19 March 2014 - Published: 13 May 2014

\begin{abstract}
Laboratory experiments were conducted to investigate the effects of water vapor on the reaction of nitric oxide with ozone in a gas-phase chemiluminescence instrument used for fast response and high sensitivity detection of atmospheric ozone. Water vapor was introduced into a constant level ozone standard and both ozone and water vapor signals were recorded at $10 \mathrm{~Hz}$. The presence of water vapor was found to reduce, i.e. quench, the ozone signal. A dimensionless correction factor was determined to be $4.15 \pm 0.14 \times 10^{-3}$, which corresponds to a $4.15 \%$ increase in the corrected ozone signal per $10 \mathrm{mmol} \mathrm{mol}^{-1}$ of co-sampled water vapor. An ozone-inert water vapor permeable membrane (a Nafion dryer with a counterflow of dry air from a compressed gas cylinder) was installed in the sampling line and was shown to remove the bulk of the water vapor in the sample air. At water vapor mole fractions above $25 \mathrm{mmol} \mathrm{mol}^{-1}$, the Nafion dryer removed over $75 \%$ of the water vapor in the sample. This reduced the required ozone signal correction from over $11 \%$ to less than $2.5 \%$. The Nafion dryer was highly effective at reducing the fast fluctuations of the water vapor signal (more than $97 \%$ ) while leaving the ozone signal unaffected, which is a crucial improvement for minimizing the quenching interference of water vapor fluxes and required density correction in the determination of ozone fluxes by the eddy covariance technique.
\end{abstract}

\section{Introduction and background}

The most widely used instrumental technique for the measurement of tropospheric ozone is by UV absorption (Williams et al., 2006). Ozone UV absorption monitors ope- rate on the principle of ozone absorbing UV light at wavelengths of around $254 \mathrm{~nm}$. These instruments are very common because of their easy operation, they maintain a stable response for a long time, only require periodic cleaning, and do not require a reactant-gas supply. Another method of measuring ozone that is gaining popularity is by differential optical absorption spectroscopy (DOAS), where average concentrations of ozone are measured within a path between the instrument telescope and a reflector array (Hönninger et al., 2004). This method requires a light path of over $1 \mathrm{~km}$; the measurement can be severely affected by particulates in the air (Evangelisti et al., 1995). The use of lightweight electrochemical concentration cell (ECC) ozonesondes has been the primary method for measuring vertical profiles of ozone in the atmosphere from airborne balloons due to their small size and low power consumption (Komhyr et al., 1995). While ECC ozonesondes are ideal for balloon-borne measurements, their sensitivity to sulfur dioxide and the need to replace the reactant solution make them less suited for continuous and stationary measurements.

While these methods have proven to be reliable for atmospheric ozone concentration measurements, their relatively slow response to atmospheric concentration changes makes them unsuitable for ozone flux measurements by the eddy covariance technique, where time resolution at frequencies faster than $\sim 1 \mathrm{~Hz}$ is desired. An ozone measurement technique with faster response, meeting the requirements for eddy covariance flux observations, is by chemiluminescence, where light emitted from the reaction of ozone with a chemical reactant is used as a measure of ozone concentration. There are several options for the chemiluminescence measurements of ozone, including wet and dry techniques that 
use organic dyes (Guesten and Heinrich, 1996; Weinheimer, 2006; Zahn et al., 2012), and gas-phase techniques that are based on the reaction of ozone with either ethylene or nitric oxide (Kleindienst et al., 1993; Williams et al., 2006; Bariteau et al., 2010). Current gas-phase chemiluminescence ozone instruments typically use nitric oxide as the reactant gas as it provides a higher signal to noise ratio than from the reaction with ethylene (Ridley et al., 1992). This ozone measurement has also become a popular method for ozone concentration (Ridley et al., 1992; Weinheimer et al., 1998; Slusher et al., 2010; Conley et al., 2011) and ozone flux (Lenschow et al., 1981, 1982; Kawa and Pearson, 1989) measurements from research aircraft. Recent developments in instrumentation for motion correction on moving platforms have enabled direct observations of open-ocean ozone fluxes using this measurement technique (Bariteau et at., 2010; Helmig et al., 2012b). The chemiluminescence reaction of ozone $\left(\mathrm{O}_{3}\right)$ and nitric oxide (NO) (reaction R1) emits light between $600 \mathrm{~nm}<\lambda<2800 \mathrm{~nm}$ that is detected with a photomultiplier tube (PMT) according to

$$
\begin{aligned}
& \mathrm{NO}+\mathrm{O}_{3} \stackrel{k_{1}}{\rightarrow} \mathrm{NO}_{2}{ }^{*}+\mathrm{O}_{2} \\
& \mathrm{NO}_{2}^{*} \stackrel{k_{2}}{\rightarrow} \mathrm{NO}_{2}+\mathrm{hv} \\
& \mathrm{NO}_{2}^{*}+\mathrm{M} \stackrel{k_{3}}{\rightarrow} \mathrm{NO}_{2}+\mathrm{M} .
\end{aligned}
$$

The excited nitrogen dioxide $\left(\mathrm{NO}_{2}{ }^{*}\right)$ reaches equilibrium through photoemission (reaction $\mathrm{R} 2$ ). $\mathrm{NO}_{2}{ }^{*}$ can also react with a molecule through collisional energy transfer, reducing it to the ground state and effectively quenching the signal (reaction R3). This quenching effect results in a reduction of the ozone signal recorded by the instrument. The chemiluminescence signal resulting from the reaction of nitric oxide and ozone is sensitive to several atmospheric molecules such as $\mathrm{H}_{2}, \mathrm{CO}_{2}$, and $\mathrm{H}_{2} \mathrm{O}$ (Matthews et al., 1977). Of these gases, water vapor is of particular concern due to its higher abundance and large variability in ambient air. An earlier study did not find that water vapor at $75 \%$ saturation, when compared to $0 \%$ saturation, affected the $\mathrm{O}_{3}-\mathrm{NO}$ chemiluminescence reaction (Fontijn et al., 1970). Subsequently, Matthews et al. (1977), found that on a per molecule basis, water vapor is more than ten times more effective at quenching the chemiluminescence signal than molecular hydrogen and more than three times more effective than carbon dioxide, which makes water the primary interferent of this ozone measurement under ambient-air conditions. In contrast to the $\mathrm{O}_{3}$-NO chemiluminescence measurement, instruments based on the reaction of ozone and ethylene reported an increase in ozone signal with water vapor (Kleindienst et al., 1993). This was determined to be due to a second compound being formed in the presence of water vapor that generates chemiluminescence.

Instead of correcting for the quenching effect of water vapor, some instruments were configured to supply a flow of water vapor to the reaction chamber to keep the effect of water vapor constant, complicating the operation of the system
(Ridley and Grahek, 1990). Another proposed method to account for the quenching effect of water was to approximate the reduction in the ozone signal as a function of the water vapor mole fraction and apply a dimensionless correction factor (Lenschow et al., 1981; Ridley et al., 1992). The humiditycorrected ozone signal is calculated by

$\mathrm{O}_{3}=\mathrm{O}_{3 \mathrm{~m}}(1+\alpha r)$,

where $\mathrm{O}_{3}$ is the corrected ozone mole fraction, $\mathrm{O}_{3 \mathrm{~m}}$ is the measured ozone volumetric mole fraction in $\mathrm{nmol} \mathrm{mol}^{-1}$, $\alpha$ is the dimensionless correction factor, and $\mathrm{r}$ is the water vapor mole fraction (expressed as the ratio of moles of water vapor to moles of dry air in mmol mol${ }^{-1}$, which is equivalent to parts per thousand). Lenschow et al. (1981) reported the $\alpha$ correction factor as $5 \times 10^{-3} \pm 1 \times 10^{-3}$ and the work of Ridley et al. (1992) further refined the value to $4.3 \times 10^{-3} \pm 0.3 \times 10^{-3}$. For example, for a typical equatorial-region open-ocean atmospheric water vapor mole fraction of $30 \mathrm{mmol} \mathrm{mol}^{-1}$ the correction accounts to $15 \%$ when using the correction factor of $5 \times 10^{-3}$. A correction of this magnitude was applied by Williams et al. (2006) in their chemiluminescence measurement of ozone. Previous work has not detailed whether and how much the correction factor is dependent on instrument configuration and operational conditions, or whether this correction is universally applicable.

Prior to the experiments described here, the correction factor had not been determined for our particular custom-built fast-response ozone instrument (FROI). Previous work with this instrument had therefore selected $\alpha=5 \times 10^{-3}$ according to Lenschow et al. (1981), which resulted in a correction of up to $25 \%$ for determining the atmospheric ozone mole fraction (Lang, 2008; Bariteau et al., 2010; Helmig et al., 2012b). Applying a correction to the ozone signal to account for the water vapor influences is particularly critical for eddy covariance calculations as these are susceptible to interferences from the atmospheric water vapor mole fraction and the water vapor flux. Our FROI has been deployed for ozone flux determination to locations vastly differing in water vapor content, from the dry arctic to the equatorial ocean (Bariteau et al., 2010; Helmig et al., 2012a, b).

Reynolds averaging (Stull, 1988; Muller, 2006) of the corrected ozone signal in Eq. (1) and the vertical component of the wind vector results in the following equation for the water vapor-corrected ozone flux:

$F_{\mathrm{O}_{3}}=(1+\alpha \bar{r}) F_{\mathrm{O}_{3 \mathrm{~m}}}+\alpha \overline{O_{3 \mathrm{~m}}} \overline{w^{\prime} r^{\prime}}$,

where $F_{\mathrm{O}_{3}}$ is the corrected ozone flux, $\alpha$ is the correction factor, $\bar{r}$ is the mean water vapor mole fraction, $F_{\mathrm{O}_{3 \mathrm{~m}}}$ is the calculated ozone flux from the measured ozone signal, and $\overline{w^{\prime} r^{\prime}}$ is the average water vapor flux. In general, there are three instances of the interaction between the water vapor flux and the ozone flux: (1) no water vapor flux - Eq. (2) is 


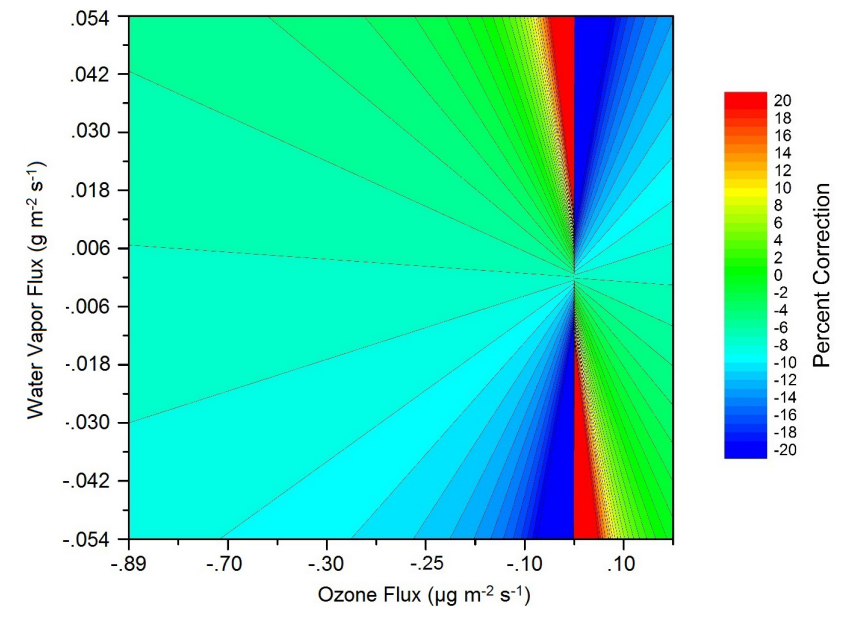

Fig. 1. Isopleths of the correction to be applied to the measured ozone flux as a function of water vapor flux using typical values for ambient-air water vapor and ozone mole fraction over the ocean, i.e. $40 \mathrm{nmol} \mathrm{mol}^{-1}$ of ozone and $18 \mathrm{mmol} \mathrm{mol}^{-1}$ of water vapor. The solid lines represent $1 \%$ increments in the correction. When the ozone fluxes and water vapor fluxes are in the same direction, the measured ozone flux has a positive error, as seen in the negative correction factor to be applied to quadrants 1 and 3 . When the ozone flux and water vapor flux are in opposite directions, there is a negative error, requiring a positive correction of the measured ozone flux, as seen in quadrants 2 and 4.

reduced to only correcting for the total atmospheric water vapor mole fraction; (2) downward water vapor flux and downward ozone flux - the uncorrected measured ozone fluxes are greater than actual ozone fluxes due to the effect of water vapor; and (3) upward water vapor flux and downward ozone flux - the uncorrected measured ozone fluxes are less than actual ozone fluxes due to the effect of water vapor fluctuations. The magnitude of ozone fluxes can vary significantly based on surface properties. Relatively large ozone fluxes, up to $-0.79 \mu \mathrm{g} \mathrm{m}^{-2} \mathrm{~s}^{-1}$, have been observed over vegetated land, such as over soybean fields (Wesely and Hicks, 2000) and over tropical forests (Cros et al., 2000). Much smaller ozone fluxes are observed over snow, ice, and water, typically ranging from -0.020 to $-0.16 \mu \mathrm{g} \mathrm{m}^{-2} \mathrm{~s}^{-1}$ (Ganzeveld et al., 2009; Helmig et al., 2009, 2012a, b). Interestingly, upward ozone fluxes of up to $0.20 \mu \mathrm{g} \mathrm{m}^{-2} \mathrm{~s}^{-1}$ have been observed in subalpine forests during the winter (Zeller, 2000). To illustrate the sensitivity of the ozone flux to the water vapor flux, the relative correction for the ozone flux calculation as a function of the water vapor flux is illustrated in Fig. 1. For this simulation, typical values for ambient-air water vapor and ozone mole fraction over the ocean were chosen, i.e. ozone was set at $40 \mathrm{nmol} \mathrm{mol}^{-1}$ and the water vapor content was set to $18 \mathrm{mmol} \mathrm{mol}^{-1}$ (Bariteau et al., 2010). The water vapor flux was varied between $\pm 5.4 \times 10^{-2} \mathrm{~g} \mathrm{~m}^{-2} \mathrm{~s}^{-1}$ (Edwards, 2007).
The green to red shaded regions illustrate conditions when the fluxes are in opposite directions. This results in a negative error of the measured ozone flux. Teal to blue regions represent conditions where the ozone and water vapor fluxes are in the same direction, which results in a positive error of the measured ozone flux. For example, an ozone flux of $-0.10 \mu \mathrm{g} \mathrm{m}^{-2} \mathrm{~s}^{-1}$ and water vapor flux of $0.06 \mathrm{~g} \mathrm{~m}^{-2} \mathrm{~s}^{-1}$ results in a corrected ozone flux of $-0.09 \mu \mathrm{g} \mathrm{m}^{-2} \mathrm{~s}^{-1}$, a difference of $11 \%$. If the water vapor flux is in the same direction as the ozone flux $\left(-0.06 \mathrm{~g} \mathrm{~m}^{-2} \mathrm{~s}^{-1}\right)$ the corrected flux is $-0.13 \mu \mathrm{g} \mathrm{m}^{-2} \mathrm{~s}^{-1}$, a difference of $29 \%$. There is a small subset of the data where there is a relatively small upward water vapor flux compared to the downward ozone flux, which results in the uncorrected measured ozone fluxes being greater than the actual ozone fluxes. This is seen in Fig. 1 as the area between where the water vapor flux is equal to zero and the dashed line for a $0 \%$ correction, showing a slight negative slope. This is due to the fact that the correction of the ozone flux depends on both the water vapor concentration and water vapor flux. During several open-ocean research cruises, Bariteau et al. (2010) calculated corrections of up to $25 \%$ to the ozone flux due to the water vapor flux. The FROI measures the mole fraction of ozone relative to air with varying amounts of water vapor. When computing ozone fluxes in the presence of water vapor, density corrections must also be applied to the ozone flux (Webb et al., 1980; Ibrom et al., 2007). The dilution correction is similar to Eq. (1) with an $\alpha$-value of 1.61, which is the ratio of the molecular weight of dry air to the molecular weight of water vapor (Bariteau et al., 2010). Dilution corrections are applied before the water flux corrections. The density correction for ozone fluxes observed in the Gulf of Mexico was an additional $8 \%$ on average (Bariteau et al., 2010). The corrections due to the water vapor flux and density changes are additive and can reach upwards of $40 \%$ combined.

Applying multiple and relatively large corrections to the ozone signal is undesirable as it leads to a greater uncertainty in the flux determination. An alternative is to selectively remove water from the sample. To achieve this goal, a Nafion drying membrane has been implemented in both chemiluminescence and UV absorption ozone instruments (Wilson and Birks, 2006; Lang, 2008; Bariteau et al., 2010; Spicer et al., 2010; Helmig et al., 2012b). The hydrophilic properties of the membrane make it permeable to water vapor without affecting the ozone signal (Wilson and Birks, 2006). The drying performance of the Nafion dryer is not uniform and depends on the type of Nafion dryer, length, sample and drying flows, and drying gas used. The amount of water vapor removed by the Nafion dryer has been found to vary from $\sim 25 \%$ to over $70 \%$ (Lang, 2008; Bariteau et al., 2010; Spicer et al., 2010). Previous analytical tests have shown that ozone is not removed by the Nafion membrane (Wilson and Birks, 2006; Spicer et al., 2010). Preliminary observations from our system indicated that the use of a Nafion drying system diminished the high-frequency water vapor 
fluctuations, which reduced the water vapor flux by $98 \%$ and eliminated the need for density and quenching corrections (Bariteau et al., 2010). The effects of the Nafion dryer on high-frequency ozone signals were not investigated in detail in that study; however, Bariteau et al. (2010) reported no apparent reductions in the ozone flux. In this paper, the effects of water vapor and the installation of a Nafion drying system on our ozone chemiluminescence instrument were studied in more depth, with a critical examination of the applicability of the correction factors determined in the earlier work by Lenschow et al. (1981) and Ridley et al. (1992).

\section{Instrumentation and methodology}

Ozone was measured by a custom-built FROI with a precision sufficient to resolve small changes in ozone mole fractions at a high temporal resolution. The FROI had a sensitivity of $\sim 2000$ counts $\mathrm{s}^{-1}$ ppbv $^{-1}$ and a background noise of 900 counts $\mathrm{s}^{-1}$, which is based on the dark current of the PMT. The dark current decreases with decreasing PMT temperature. The background noise was 3500 counts s$^{-1}$ at $-20^{\circ} \mathrm{C}, 900$ counts s$^{-1}$ at $-30^{\circ} \mathrm{C}$, and 400 counts s $^{-1}$ at $-35^{\circ} \mathrm{C}$. The PMT cooler could not keep the temperature stable at $-35^{\circ} \mathrm{C}$, so $-30^{\circ} \mathrm{C}$ was used throughout the experiments. Details and a schematic of the FROI have been published by Bariteau et al. (2010) (see Fig. 1 in this reference for a schematic of the FROI). Sample air was pulled through a Teflon ${ }^{\circledR}$ (PFA, perfluoroalkoxy copolymer) line controlled to $1.5 \mathrm{~L} \mathrm{~min}^{-1}$ by a mass flow controller (MFC). All ozone sample tubing was $0.64 \mathrm{~cm}$ outer diameter Teflon ${ }^{\circledR}$ tubing. Nitric oxide reactant gas flowed through stainless steel tubing and was controlled at $3 \mathrm{~mL} \mathrm{~min}^{-1}$. The sample and NO were mixed in a $44 \mathrm{~cm}^{3}$ gold-plated reaction chamber. The reaction chamber temperature was maintained at $30^{\circ} \mathrm{C}$ by a heater and temperature controller. An integrated PMT housing Peltier cooler maintained the PMT temperature at $-30^{\circ} \mathrm{C}$ (Model C10372, Hamamatsu Photonics K. K., Shizuoka, Japan). The reaction chamber pressure was controlled to 18 Torr by a pressure controller (Model UPC 1300, Celerity, Hatfield, PA, USA) downstream of the reaction chamber, which ensured that the instrument response was insensitive to fluctuations in the sample delivery flow rate. Photons were counted by a PMT (Model R2257P, Hamamatsu Photonics K. K., Shizuoka, Japan) with a cutoff filter (Model RG-610, Newport Industrial Glass, Stanton, CA) removing radiation with wavelengths of less than $600 \mathrm{~nm}$. The FROI was calibrated against a commercial UV absorption instrument (Model TEI 49i, Thermo Scientific, Franklyn, MA, USA). This UV-instrument was referenced against the ozone standard at the Global Monitoring Division (GMD), National Oceanic and Atmospheric Administration (NOAA), Boulder, Colorado.
In typical field deployments, the measurement of surface ozone fluxes is accomplished by the use of the FROI and a sonic anemometer. The sampling inlet for the FROI is located a few centimeters behind the head of the sonic anemometer, minimizing disturbances due to the sampling line. Sample air was pulled through a $30 \mathrm{~m}$ Teflon-PFA line from the inlet to the instrument. There is a delay in the acquisition of the ozone signal in the FROI due to the transport time between the inlet and the reaction chamber. The lag time is regularly determined by using a "puff-system", where a small quantity of NO is injected at the tubing inlet, causing the removal of ozone by the reaction with NO during the transport to the reaction chamber (Bariteau et al., 2010). The time when the electronically actuated valve is opened is recorded in the data acquisition system. The delay between the electrical pulse and the drop-in-the-ozone signal recorded with the instrument allows for the determination of the lag time. Flow rates are set to keep a turbulent flow regime in the sampling tubing. The addition of a Nafion dryer (Model MD-110-96F, Perma Pure LLC, Toms River, NJ, USA) (and its bends and curves) enhances mixing within the tubing (Lenschow and Raupach, 1991). Prior experiments with a tubing length of $30 \mathrm{~m}$ and a flow rate of $12.5 \mathrm{~L} \mathrm{~min}^{-1}$ gave a mean lag time of $4.76 \mathrm{~s}$, with a standard deviation of $\sim 0.12 \mathrm{~s}$ during repeated puff tests and less than $0.2 \mathrm{~s}$ during 2-4-week-long campaigns. The addition of the Nafion dryer increased the mean lag time to $5.14 \mathrm{~s}$ and the standard deviation to $\sim 0.13 \mathrm{~s}$. The time required for the ozone signal to drop to $1 / \mathrm{e}$ of its initial value is defined as the instrument response time. This response time is based on a number of instrumental operating variables, including the reaction chamber volume and pressure, purge rate, PMT response, and the electronic processing of the signal. Zahn et al. (2012) calculated a reaction time as the time required for the ozone signal to drop by $90 \%$ and showed that increasing the sample tubing length increased the response time for a fixed flow rate. In our instrument, the response time without the Nafion dryer installed was $0.31 \pm 0.03 \mathrm{~s}$. With the addition of the Nafion dryer, the response time was $0.32 \pm 0.03 \mathrm{~s}$. Consequently, under the experimental conditions applied here, the addition of the Nafion dryer did not have a statistically significant effect on the response time.

A detailed schematic of the laboratory experimental setup is shown in Fig. 2. Water vapor measurements were achieved with a closed-path infrared hygrometer (Model LI-7000, LICOR Inc., Lincoln, NE, USA). The sample flow for the LI7000 was controlled at $1.5 \mathrm{~L} \mathrm{~min}^{-1}$ using a MFC. The LI7000 recorded water vapor data in $\mathrm{mmol} \mathrm{mol}^{-1}$. A water removal system was designed around a $2.44 \mathrm{~m}-1 \mathrm{ong}, 0.64 \mathrm{~cm}$ outer diameter Nafion dryer tubing. The pressure in the dryer outer annual space was maintained at a lower pressure to prevent the collapse of the inner membrane. The sample flow and dryer flow ran in opposite directions. The Nafion dryer system included a rotameter and needle valve for regulating the dryer flow, a drying column filled with $\mathrm{CaSO}_{4}$ 


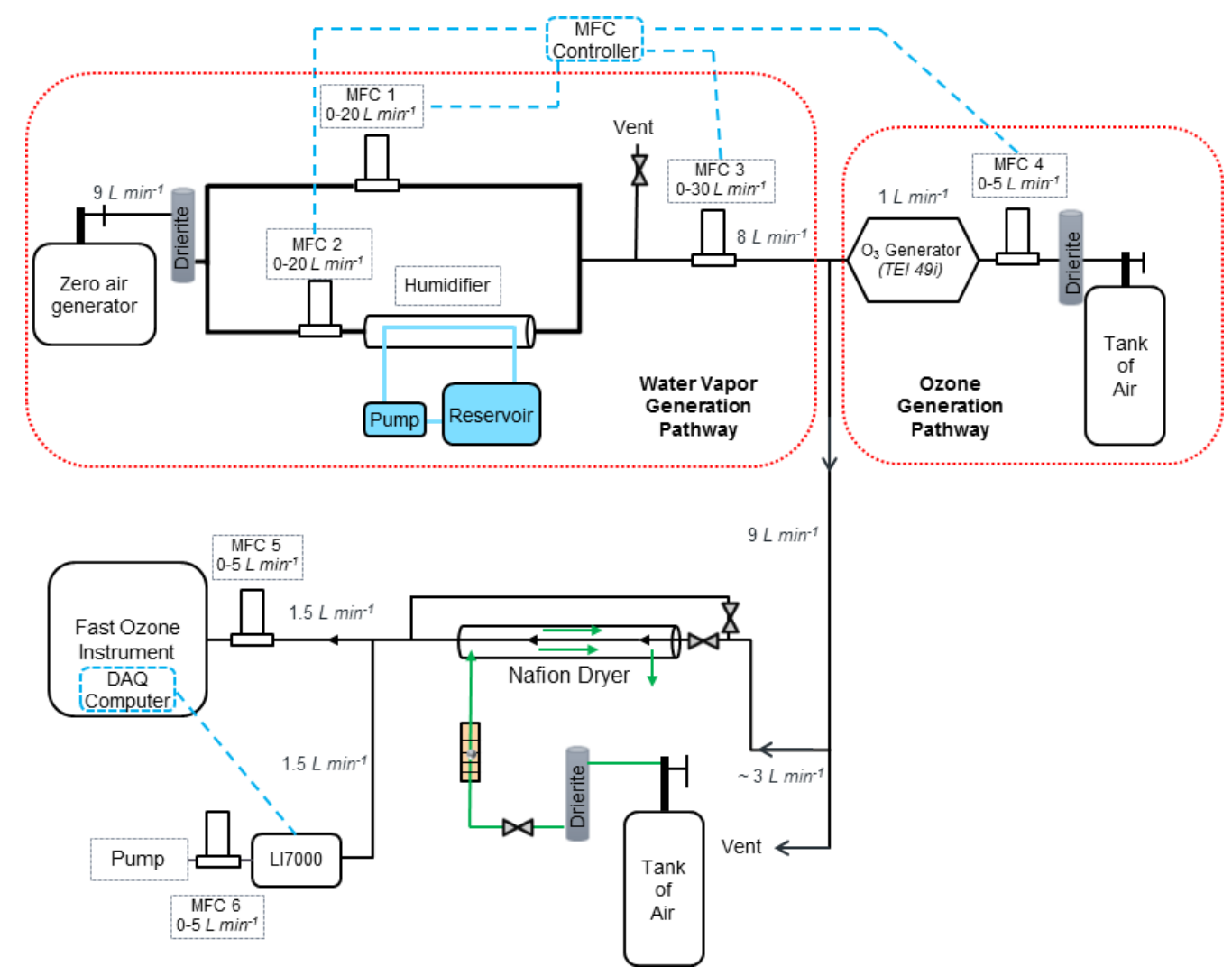

Fig. 2. Schematic of the laboratory setup. The red box in the upper left of the figure shows where the sample air was humidified. Ambient air was scrubbed through a zero-air generator and run through a drying agent. The flow was varied through mass flow controller (MFC) 1 to produce dry air and MFC 2 to produce humid air. The humidifier was a Nafion membrane containing liquid water in the inner tube and the sample flow through the outer shell. Excess flow was released through the vent with a flow restrictor. MFC 3 controlled the flow to $8 \mathrm{~L} \mathrm{~min}^{-1}$. This air was mixed with ozone-enriched air from the TEI 49i ozone generator (red box in upper right of figure). Sample air was provided from a tank of dry breathing air. The flow through the ozone generator was controlled to $1 \mathrm{~L} \mathrm{~min}^{-1}$. The Nafion drying system, FROI and LI-7000 are shown at the lower portion of the figure. Switching valves directed the flow through or around the Nafion dryer. MFCs 5 and 6 controlled the flow to the FROI and LI-7000 and were set at $1.5 \mathrm{~L} \mathrm{~min}^{-1}$. All data were collected on the data acquisition computer housed in the FROI.

(W. A. Hammond Drierite Co. LTD, OH, USA), and a tank of breathing-air grade compressed gas. The water vapor content in the breathing-air tank was less than $0.03 \mathrm{mmol} \mathrm{mol}^{-1}$. The flow of the drying air in the Nafion system was maintained at between two and three times the sample flow. The sample flow passing through the Nafion dryer was $3.0 \mathrm{~L} \mathrm{~min}^{-1}$ (FROI + LI-7000).

A tank of breathing air supplied ozone-free air to the TEI $49 \mathrm{i}$ which was used for generating ozone. Ozone was produced by setting the TEI 49i generator to a constant ozone output level. The flow rate was held constant at $1.0 \mathrm{~L} \mathrm{~min}^{-1}$ by MFC 4 . The ozone output was set to different levels by adjusting the intensity of the UV light source inside the TEI 49i. The resulting ozone output was checked regularly with the TEI $49 \mathrm{i}$ and found to be stable based on the comparison of measured ozone levels prior to and after experiments that used a particular ozone output level. The ozone generation process was kept separate from the humidifying process to ensure constant ozone production regardless of water vapor content. The ability to regulate the water vapor content in the air was accomplished by using a "zero-air" generator and a Drierite column and by changing the split ratio and balancing the total flow between MFC 1 and MFC 2. The combined flow through these two MFC was held constant at $\sim 9 \mathrm{~L} \mathrm{~min}^{-1}$. The introduction of water vapor into the sample air was accomplished by operating a Nafion dryer in reverse mode: liquid water was pumped through the inner tubing while dry air regulated by MFC 2 flowed in the outer tube. Maximum water vapor mole fractions were achieved when MFC 2 was set to $9.0 \mathrm{~L} \mathrm{~min}^{-1}$ and MFC 1 was closed. MFC 3 was set to $8.0 \mathrm{~L} \mathrm{~min}^{-1}$, leaving an excess flow to the vent of $1 \mathrm{~L} \mathrm{~min}^{-1}$. This configuration allowed for controlling a continuous range of water vapor mole fractions of between $<0.1$ and $28 \mathrm{mmol} \mathrm{mol}^{-1}$. 
This study used four ozone $(0,30,60$, and $\left.100 \mathrm{nmol} \mathrm{mol}^{-1}\right)$ and six water vapor mole fraction levels $\left(<0.1,6,12,18,23\right.$, and $\left.27 \mathrm{mmol} \mathrm{mol}^{-1}\right)$ to mimic a range of atmospheric conditions. These levels were tested with and without the Nafion dryer installed, yielding 48 sampling periods. Ozone was set to one of the four levels, then the water vapor was varied across each of the six water vapor levels. Water vapor levels were varied both from high to low and low to high. Each sampling period was run for at least $15 \mathrm{~min}$ after both the water vapor and ozone signals equilibrated to new conditions. All data were sampled and recorded at $10 \mathrm{~Hz}$. Data from each sampling period were reduced to $15 \mathrm{~min}$ for consistency between sampling periods.

In our experimental configuration MFCs 3 and 5 were subjected to sample air with varying water vapor mole fraction. The changing humidity in the sample flow bears the potential to effect the ability of the MFC to maintain a constant flow rate, resulting possibly in a difference between the MFC set point flow and the actual flow rate. This effect could potentially bias the results from these experiments, in that changes in flow rate and dilution ratio could mistakenly be interpreted as a change in the FROI detection sensitivity. It has previously been noted that the effect of water vapor on MFC flow rates is nonlinear, making the scaling relations of the MFC particularly challenging (Wang, 2012; B. Darby, Coastal Instruments, personal communication, 5 March 2013). In order to investigate the effect of water vapor on MFC flow rates, MFC 3, a Tylan FC-2900 with a flow range of 0 to $30 \mathrm{~L} \mathrm{~min}^{-1}$, was subjected to variable humidity levels while the set point flow rate was kept constant at $8 \mathrm{~L} \mathrm{~min}{ }^{-1}$. Reference flow rates were determined with a bubble meter. Flow rates determined with the bubble meter were first corrected for the increase in the flow reading due to the moisturizing of the air flow in the bubble meter, then corrected for temperature and pressure to yield mass flow rates at standard conditions, and then compared with the set point flow rates of the mass flow controller. For dry air, at an MFC set point of $8 \mathrm{~L} \mathrm{~min}^{-1}$, the MFC displayed flow was $7.98 \mathrm{~L} \mathrm{~min}^{-1}$ while the bubble meter calibration gave $8.12 \mathrm{~L} \mathrm{~min}^{-1}$. Water vapor was then introduced into the sample flow at five levels between 4 and $26 \mathrm{mmol} \mathrm{mol}^{-1}$ and 20 bubble meter flow readings were recorded at each level (Appendix Fig. A1). At all tested water vapor levels at and above $0.4 \mathrm{mmol} \mathrm{mol}^{-1}$, while the MFC reported that the flow remained constant at $7.98 \mathrm{~L} \mathrm{~min}^{-1}$, the average flow rate determined with the bubble meter was $7.93 \mathrm{~L} \mathrm{~min}^{-1}$, a drop of $2.3 \%$ compared to the dry air sampling. A one-way analysis of variance (ANOVA) found this difference to be statistically significant at the $p<0.05$ level, $F(5,114)=15.9$, $p=1.35 \times 10^{-9}$. Furthermore, post hoc comparison using the Tukey test (Hsu, 1996) indicated that the mean bubblemeter-reported flow for the dry air was significantly different than the individual results at each of the humidified air levels. The same calculations revealed that there was no significant difference in the mean flow between any of the tested humidified air levels. The same analysis was conducted on MFC 5, a Tylan FC-260 with a range of 0 to $5 \mathrm{~L} \mathrm{~min}^{-1}$, yielding similar results, i.e. a drop of $2.6 \%$ (Appendix Fig. A2) and statistical significance. Taken together, these results indicate that the MFCs exhibit a significant drop in flow between dry and humidified air (2.3-2.6\%), but that flows are not affected over a wide range of humidity once a threshold value (in our case $\sim 4 \mathrm{mmol} \mathrm{mol}^{-1}$ ) has been exceeded. For this manuscript, flow rates from experiments with dry air were corrected for this bias, but no further corrections were applied to experiments conducted at humidities $>4 \mathrm{mmol} \mathrm{mol}^{-1}$. It is noteworthy that in the experimental setup used here, the bias of MFC 3 was attenuated somewhat as the resulting ozone mole fraction delivered depends on the flow ratio of MFC 4/(MFC $3+$ MFC 4). Furthermore, the MFC biases of MFC 3 and MFC 5 cancel each other out to a significant degree $(\sim 75 \%)$. When MFC 3 experienced a drop in flow going from dry to moist air, the ozone mole fraction in the ozone standard sample increased slightly from the change in the dilution ratio while the output from the $49 \mathrm{i}$ remained constant. The response of MFC 5 in this transition was a slight reduction of the flow provided to the FROI, causing a reduction in the FROI response. The net effect of the MFC 3 and MFC 5 flow changes between moist and dry air on the ozone signal was calculated as $0.54 \%$.

Experiments under ambient conditions were conducted to test the effect of the Nafion dryer on high-frequency fluctuations of the water vapor signal. This experiment took place behind the NOAA David Skaggs Research Center in Boulder, CO, in October 2008. The footprint of the sampling location consisted of a small parking lot surrounded by surface vegetation. The same FROI and Nafion drying system setup were used in this experimental setup. Water vapor was measured by two LI-7500 (LI-COR Inc., Lincoln, NE, USA) hygrometers. Each of these hygrometers was converted to closedpath instruments by inserting the calibration tube between the sapphire-glass windows. The FROI and the two LI-7500s were housed in a container for weather protection. Ambient air was drawn through a $23 \mathrm{~m}$ sampling line with an inlet located at $4 \mathrm{~m}$ height on a meteorological tower. A Teflon ${ }^{\circledR}$ membrane filter ( $5 \mu \mathrm{m}$, Millipore, Billerica, MA, USA) was used during ambient-air measurements to prevent contamination of the tubing due to large airborne particles. The air passed through one LI-7500, then through the Nafion dryer followed by the other LI-7500, before sampling by the FROI. Prior to the experiment, an intercomparison of both LI-7500s was conducted to determine the offset between the instruments. The ambient-air ozone mole fraction varied between 36 and $42 \mathrm{nmol} \mathrm{mol}^{-1}$ and the water vapor mole fraction varied between 4 and $7 \mathrm{mmol} \mathrm{mol}^{-1}$. 


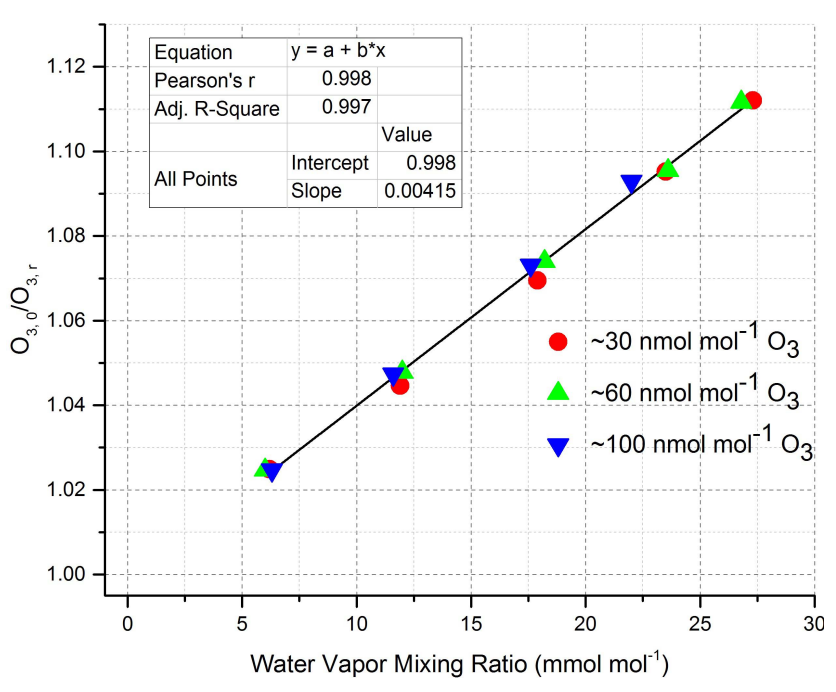

Fig. 3. Ratio of ozone signal in dry air (water vapor levels less than $\left.0.1 \mathrm{mmol} \mathrm{mol}^{-1}\left(\mathrm{O}_{3,0}\right)\right)$ to ozone signal at water vapor level $r$ $\left(\mathrm{O}_{3, r}\right)$ versus water vapor mole fraction. The points are color-coded according to the amount of ozone in the sample air. The solid lines represent results from linear regression analyses. The results from the linear regression analyses are shown in the table insert.

\section{Results and discussion}

\subsection{Effects of water vapor on the chemiluminescence ozone signal}

The water vapor mole fraction was varied across different ozone levels in order to determine the appropriate correction factor, $\alpha$, for this instrument and to evaluate how the correction factor compares with previously reported results for other instruments. To determine the correction factor $\alpha$, a rewrite of Eq. (1) was used, where the corrected ozone mole fraction was set equal to the ozone signal at a water vapor mole fraction of less than $0.1 \mathrm{mmol} \mathrm{mol}^{-1}\left(\mathrm{O}_{3,0}\right)$ and the measured ozone was set equal to the ozone signal at varying water vapor mixing ratios $r\left(\mathrm{O}_{3, r}\right)$. At each ozone level, the correction factor was calculated at each water vapor level with pairwise combinations of $\mathrm{O}_{3,0}$ and $\mathrm{O}_{3, r}$. The correction factor, $\alpha$, was determined by the slope of the linear regression analysis, where the ratio $\mathrm{O}_{3,0} / \mathrm{O}_{3, r}$ was plotted against the water vapor mole fraction as shown in Fig. 3. A consistent pattern with a decrease in the ozone signal caused by an increase of water vapor was seen when water vapor was introduced to ozone-enriched air. Direct observations from this experiment showing the average ozone signal loss for each average water vapor level are presented in Appendix Table A1; the summary of these results is shown in Fig. 3. At the highest water vapor mole fractions applied in these experiments, the ozone signal had a negative bias of over $11 \%$.

The slope from the linear regression analysis of all points in Fig. 3 gave a value of $4.15 \times 10^{-3}$ for $\alpha$ with a $95 \%$ confidence interval of $0.14 \times 10^{-3}$. This result is within the range

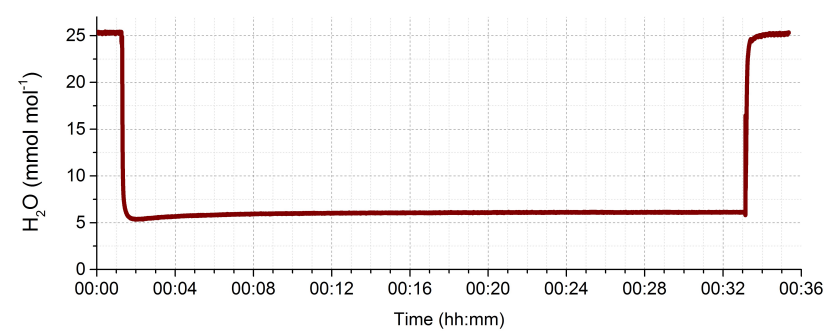

Fig. 4. The water vapor signal measured with the LI-7000 hygrometer before, during, and after switching the Nafion dryer into the sample flow path.

given by Lenschow et al. $(1981)\left(5 \times 10^{-3} \pm 1 \times 10^{-3}\right)$ and Ridley et al. (1992) $\left(4.3 \times 10^{-3} \pm 0.3 \times 10^{-3}\right)$. The acquisition rate of our instrument was $10 \mathrm{~Hz}$; Lenschow et al. (1981) used a sampling frequency of $20 \mathrm{~Hz}$ and Ridley et al. (1992) sampled at $12 \mathrm{~Hz}$. Despite their reaction chamber being half the size of ours at $17 \mathrm{~cm}^{3}$, it yielded a similar signal response under their operating conditions as our instrument, with a sensitivity of 2000 counts s ${ }^{-1} \mathrm{ppbv}^{-1}$. Ridley et al. (1992) used a sample flow of $0.18 \mathrm{~L} \mathrm{~min}^{-1}$ and a reactant flow of $1.5 \mathrm{~mL} \mathrm{~min}^{-1}$, which resulted in a ratio of the sample flow to the reactant flow of 120 . Our instrument operated with a sample flow of $1.5 \mathrm{~L} \mathrm{~min}^{-1}$ and a reactant flow of $3 \mathrm{~mL} \mathrm{~min}^{-1}$, yielding a ratio of 500. Even though the ratio determined from the Ridley et al. (1992) flow rates was more than four times smaller than the ratio of flow rates used in this experiment, similar correction factors were determined. The important conclusion from these comparisons is that, despite these differences in the instrument configurations, ratios of sample to reactant flows, and data acquisition rates, the correction factors determined by these studies all agree within the margin of error provided by each study.

\subsection{The removal of water vapor with a Nafion drying system}

The Nafion dryer was installed in the sample line (Fig. 2) upstream of the FROI and LI-7000. Switching valves allowed for the flow to pass through or bypass the Nafion dryer. The experiment from the previous section was repeated with the addition of the Nafion drying system. A time series of the water vapor mole fraction recordings in the sample flow as it first bypassed the Nafion dryer and then flowed through the Nafion dryer is shown in Fig. 4. In Fig. 4 the flow bypassed the Nafion dryer for the first $2 \mathrm{~min}$; during that time the LI-7000 recorded $25.4 \mathrm{mmol} \mathrm{mol}^{-1}$. After 2 min the flow was switched to the Nafion dryer and the water vapor mole fraction dropped below $6.0 \mathrm{mmol} \mathrm{mol}^{-1}$. It took between 6 and $10 \mathrm{~min}$ for the water vapor to slightly increase again and then equilibrate at $6.1 \mathrm{mmol} \mathrm{mol}^{-1}$. The flow was then switched back to bypass the Nafion dryer again to ensure reproducible water vapor conditions throughout the 


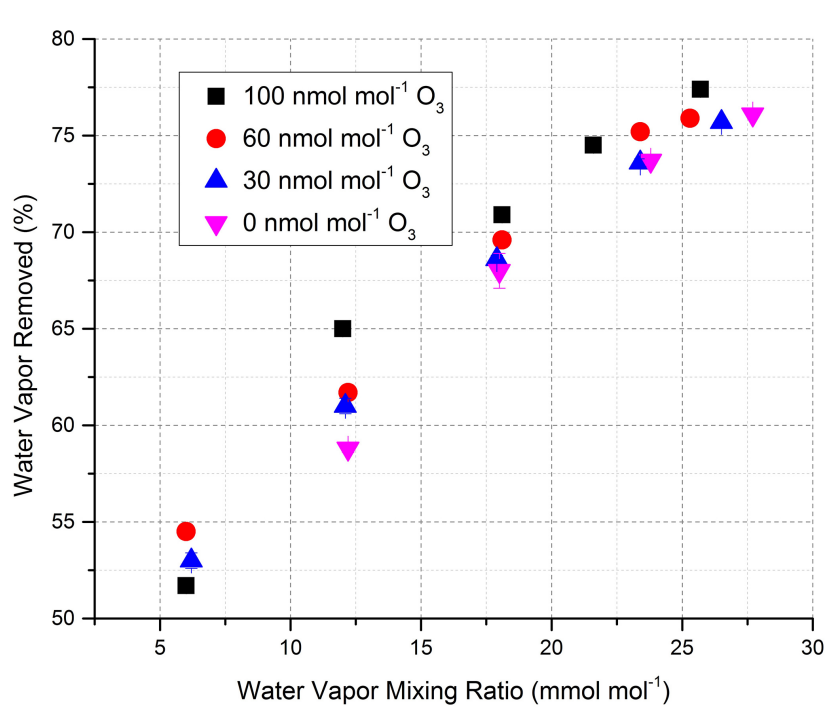

Fig. 5. Fraction of water vapor removed by the Nafion dryer versus the absolute water vapor mole fraction upstream from the Nafion dryer. Data are color-coded according to ozone level.

experiment. This behavior was repeatable during operation of the Nafion drying system over a period of several days.

The amount of water vapor removed from the sample air under the range of applied conditions is shown in Fig. 5. The drying efficiency was consistent across ozone levels. The Nafion dryer removed $50 \%$ of the water at the lower water vapor mole fractions. This is a higher rate than what was reported in a previous study with this Nafion setup where a $28 \%$ removal rate of water vapor through the Nafion system using ambient air with a water vapor mole fraction of $\sim 5 \mathrm{mmol} \mathrm{mol}^{-1}$ was observed (Lang, 2008; Bariteau et al., 2010). Under the laboratory conditions tested here, the Nafion dryer became more efficient at higher water vapor mole fractions, removing up to $78 \%$ of the water vapor in the sample air at the highest humidity conditions that could be tested.

Additional tests were performed to determine the optimum configuration for the Nafion drying system. During the above described experiments, the sample flow through the Nafion drying system was $3.0 \mathrm{~L} \mathrm{~min}^{-1}$ and the drying flow was set at $9.0 \mathrm{~L} \mathrm{~min}^{-1}$. The drying flow was lowered to $6.0 \mathrm{~L} \mathrm{~min}^{-1}$ to investigate the relationship between dryer flow and water vapor removal. The comparison between these two dryer flows revealed a statistical difference in the amount of water vapor removed. The $9.0 \mathrm{~L} \mathrm{~min}^{-1}$ drying flow removed $77.4 \%$ of the water vapor while the lower drying flow of $6.0 \mathrm{~L} \mathrm{~min}^{-1}$ removed $75.0 \%$. There was no statistical difference in the ozone signals between the high drying flow rate and low drying flow rate.

A comparison was also made between the $2.44 \mathrm{~m}$-long (used for the entirety of this experiment) and a $1.22 \mathrm{~m}$-long dryer under otherwise identical operating conditions. At a water vapor mole fraction of $26 \mathrm{mmol} \mathrm{mol}^{-1}$, the $2.44 \mathrm{~m}$ dryer removed $\sim 78 \%$ while the $1.22 \mathrm{~m}$ dryer removed $71 \%$ of the supplied amount of water vapor. Obviously, the removal rate of water vapor does not scale linearly with the drying-gas flow rate and the length of the Nafion dryer. It is important to note that drying efficiency is variable and dependent on multiple operational conditions that do not scale linearly.

\subsection{Effect of the Nafion dryer on the ozone signal}

First, we tested whether there was a loss of ozone as it passed through the Nafion dryer by comparing three configurations: (1) a control case without the Nafion dryer installed, (2) Nafion dryer installed with a drying flow rate of $0.0 \mathrm{~L} \mathrm{~min}^{-1}$, and (3) Nafion dryer installed with a drying flow rate of $9.0 \mathrm{~L} \mathrm{~min}{ }^{-1}$. All three cases used a dry sample flow containing $<0.1 \mathrm{mmol} \mathrm{mol}^{-1}$ of water vapor and $60 \mathrm{nmol} \mathrm{mol}^{-1}$ of ozone. The mean ozone signals measured for these three setups were basically the same, varying by 40 counts s$^{-1}\left(0.03 \%\right.$ of 130000 counts s$\left.^{-1}\right)$, which is within the sampling noise of the instrument and not statistically different. This confirmed previous research that reported that ozone passes through the Nafion dryer without any noticeable losses (Wilson and Birks, 2006; Spicer et al., 2010).

After confirming that there was no ozone loss in the Nafion dryer, we investigated how much of the ozone signal loss seen in the experiments described above is restored by passing a humidified sample flow through the dryer. When using a Nafion drying system, there are two effects that need to be considered: (1) an enrichment (i.e. increase in mole fraction) of ozone resulting from the removal of water molecules and (2) the reduction of the quenching effect occurring in the reaction chamber.

The Nafion drying system operates on the principle of removing molecules of water vapor from the sample line by permeation through a semipermeable membrane. Since this causes a reduction of the total amount of molecules while the number of ozone molecules remains constant, the use of the dryer results in an enrichment of ozone, i.e. an increase in the ozone mole fraction and the signal from the FROI. The enrichment effect is expected to be equal to the fraction of water vapor molecules removed by the Nafion dryer. In the previous section it was shown, for instance, that at water vapor mole fractions of $\sim 25 \mathrm{mmol} \mathrm{mol}^{-1}$, the Nafion dryer removed $\sim 78 \%$ of the water vapor, equivalent to $\sim 20 \mathrm{mmol} \mathrm{mol}^{-1}$ (or 20 parts per thousand, i.e. $2 \%$ ). This enrichment would consequently cause an increase in the FROI signal of $2 \%$. Figure 6 displays the inferred ozone enrichment as a function of the water vapor content (as measured upstream of the Nafion dryer), ranging from 0.3 to $2 \%$ under the water vapor mole fractions applied here.

The ozone signal that is restored when using the Nafion dryer was determined by comparing results from three different cases. Case 1 is the sample flow containing 
Table 1. Comparison of measured ozone signals (mean of 15 min data) at $30 \mathrm{nmol} \mathrm{mol}^{-1}$ (in counts s${ }^{-1}$ ) for cases 1 , 2, and 3 , before and after applying each correction term.

\begin{tabular}{|c|c|c|c|}
\hline $\begin{array}{l}\text { Case } 1 \\
\text { Water vapor } \\
\text { Mole fraction }\end{array}$ & $\begin{array}{r}\text { Case } 2 \\
<0.1 \mathrm{mmol} \mathrm{mol}^{-1} \\
\text { no Nafion dryer }\end{array}$ & $\begin{array}{r}\text { Case } 3 \\
6.04 \mathrm{mmol} \mathrm{mol}^{-1} \\
\text { no Nafion dryer }\end{array}$ & $\begin{array}{r}26.5 \mathrm{mmol} \mathrm{mol}^{-1} \\
\text { Nafion installed }\end{array}$ \\
\hline Measured counts & $60645^{*}$ & 59135 & 60267 \\
\hline Corrected for enrichment & N/A** & N/A & 59079 \\
\hline Corrected for quenching & N/A & 60617 & 60648 \\
\hline
\end{tabular}

* Calculated from a raw count of 60975 after correcting for the dry air flow biases of MFC 3 and MFC 5. ** Not applicable.

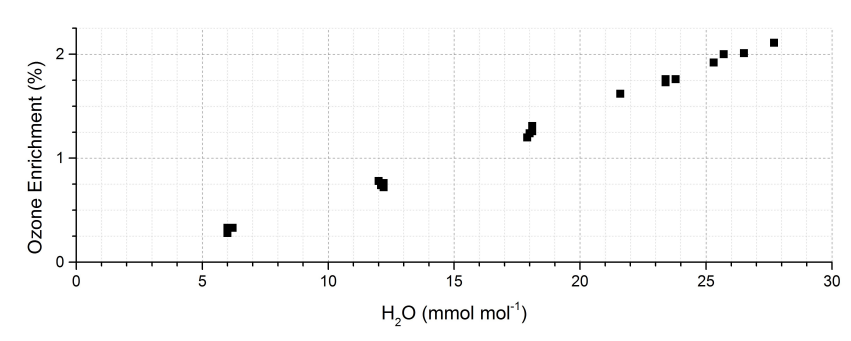

Fig. 6. Increase in the ozone signal from the removal of water vapor molecules by the Nafion dryer as a function of the water vapor mole fraction in the sample air, using the drying efficiency ratios shown in Fig. 5.

$30 \mathrm{nmol} \mathrm{mol}^{-1}$ of ozone in dry air and $<0.1 \mathrm{mmol} \mathrm{mol}^{-1}$ of water vapor, without the sample passing through the Nafion dryer. Case 2 is a humidified sample containing $30 \mathrm{nmol} \mathrm{mol}^{-1}$ of ozone and a water vapor mole fraction of $6.04 \mathrm{mmol} \mathrm{mol}^{-1}$, without passing through the Nafion dryer. Case 3 is for a sample flow with the Nafion dryer installed, containing $30 \mathrm{nmol} \mathrm{mol}^{-1}$ of ozone, $26.5 \mathrm{mmol} \mathrm{mol}^{-1}$ of water vapor upstream of the Nafion dryer, and $6.04 \mathrm{mmol} \mathrm{mol}^{-1}$ of water vapor downstream of the Nafion dryer. In cases 2 and 3 , the amount of water vapor entering the FROI reaction chamber was very similar, at $\sim 6 \mathrm{mmol} \mathrm{mol}^{-1}$. In theory, the ozone signal from case 2 should be equal to the ozone signal from case 1 after correcting for the quenching effect, and case 3 should agree with case 1 after correcting for the enrichment and quenching.

For case 1 , the FROI signal was 60645 counts s$^{-1}$ (Table 1). For case 2, the corrected ozone signal was determined from the measured 59135 counts s$^{-1}$ by using Eq. (4), $\alpha=4.15 \times 10^{-3}$, and $r=6.04 \mathrm{mmol} \mathrm{mol}^{-1}$ of water vapor. This yields a corrected ozone signal of 60617 counts $\mathrm{s}^{-1}$. The ozone signal for case 3 required corrections for both enrichment and quenching. The difference in water vapor mole fractions upstream and downstream of the Nafion dryer was $20.1 \mathrm{mmol} \mathrm{mol}^{-1}$ of water vapor, which corresponded to $2.01 \%$ of the total molecules in the sample flow being removed by the Nafion dryer. The measured ozone signal was 60267 counts s$^{-1}$, corresponding to an ozone signal of 59079 counts s $^{-1}$ after this correction. In order to account for the quenching effect, Eq. (4) was applied, with $\mathrm{O}_{3 \mathrm{~m}}=59079$ counts s $^{-1}, \alpha=4.15 \times 10^{-3}$, and $r=6.4 \mathrm{mmol} \mathrm{mol}^{-1}$ of water vapor. This calculation resulted in a corrected ozone signal of 60648 counts s $^{-1}$.

With these considerations, the three cases gave close agreement, with a difference between the three cases of less than 32 counts s${ }^{-1}$ (or $0.02 \mathrm{nmol} \mathrm{mol}^{-1}$ of ozone), which is well within the precision of the FROI. This consistency confirms the correctness of the determined quenching effect, developed correction algorithms, and the efficiency of the Nafion dryer in mitigating the quenching effects in the FROI ozone detection.

\subsection{Reduction of atmospheric water vapor high -frequency signals}

The high sampling frequency of the FROI and LI-7500 allowed for the investigation of high-frequency behavior of the ozone and water signal with use of the Nafion dryer, specifically the reduction of water vapor fluctuations that determine the water vapor flux in Eq. (3). The following analyses are based on the experiments conducted on the mesa behind the NOAA David Skaggs Research Center. The sample air contained $\sim 40 \mathrm{nmol} \mathrm{mol}^{-1}$ of ozone and $\sim 6.0 \mathrm{mmol} \mathrm{mol}^{-1}$ of water vapor.

The water vapor power spectra shown in Fig. 7a with and without the Nafion dryer illustrate that the Nafion dryer was very efficient in damping the high-frequency water vapor signal below $2 \mathrm{~Hz}$; the difference is maximized between 0.03 and $0.5 \mathrm{~Hz}$. The water vapor spectrum obtained without the Nafion dryer has contributions over a wide range of frequencies. White noise was seen at frequencies higher than $2 \mathrm{~Hz}$. The water vapor spectrum with the Nafion dryer installed has its primary contribution at frequencies less than $10^{-2} \mathrm{~Hz}$ and a reduction of the frequencies higher than $10^{-2} \mathrm{~Hz}$ when compared to the water vapor signal without the Nafion dryer. The ratio of the integrals of the power spectra showed a $56 \%$ reduction of the water vapor mole fraction, which confirmed the results in Fig. 5.

The frequency response spectrum in Fig. 7c shows the coherency between the water vapor signals with and without 


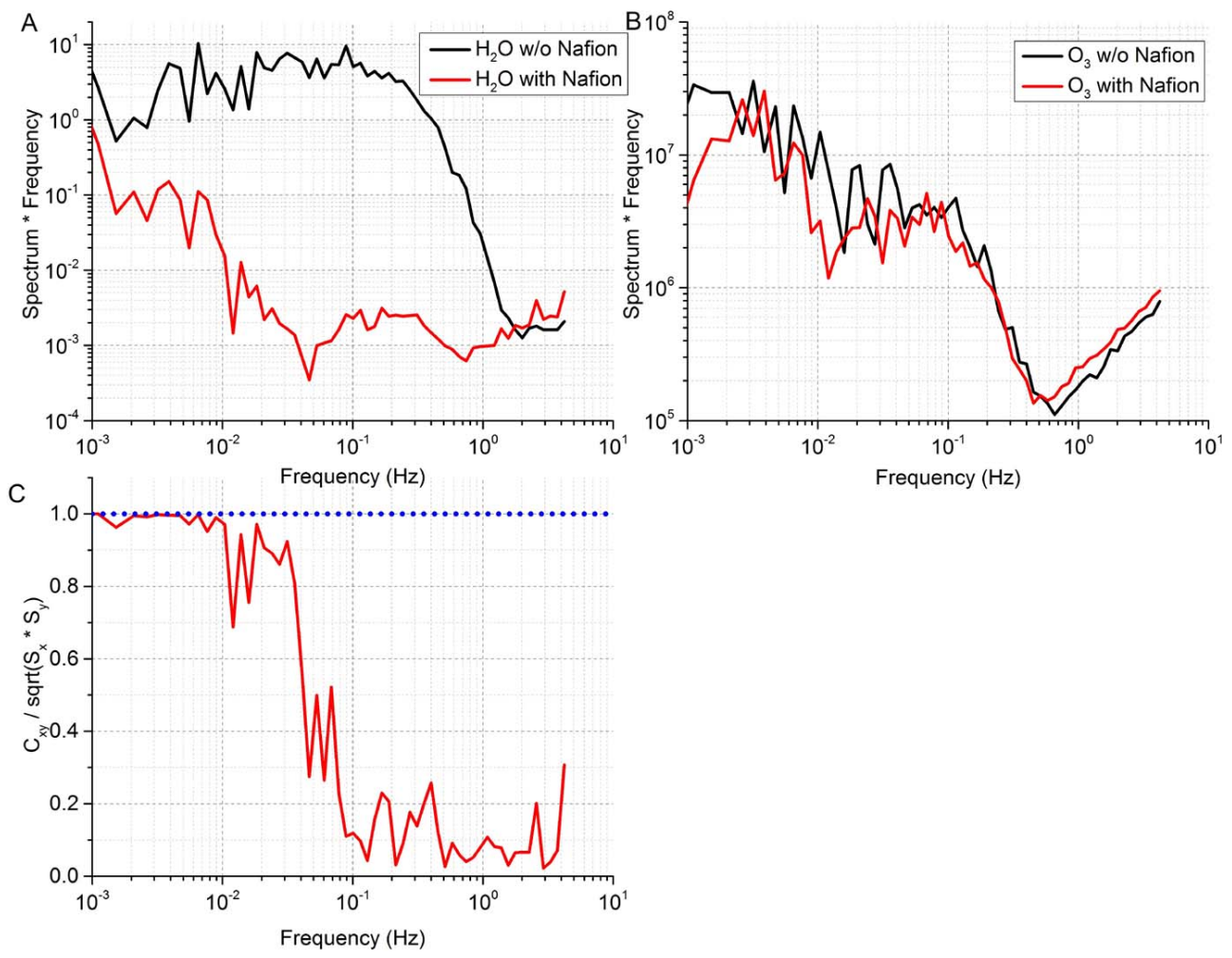

Fig. 7. Spectral distribution plots using two consecutive $2 \mathrm{~h}$ periods of data from the same hydrometer and ozone instrument, with and without the Nafion dryer. All plots use the same $x$ axis range. The sample air contained $\sim 40 \mathrm{nmol} \mathrm{mol}^{-1}$ of ozone and $\sim 6.0 \mathrm{mmol} \mathrm{mol}{ }^{-1}$ of water vapor in the flow path. (A) Power spectra of ambient water vapor with (red) and without (black) the Nafion drying system. (B) Power spectra of the ozone signal with (red) and without (black) the Nafion drying system. (C) Coherency spectral distribution of the ambient water vapor signal.

a Nafion dryer. The coherency is the ratio of the cospectra between the two water vapor signals and the square root of the product of the power spectra. A coherency value of 1 is representative of a high correlation between two signals at a given frequency. The water vapor signals have high coherency between $10^{-3}$ and $10^{-2} \mathrm{~Hz}$, a decrease between $10^{-2}$ and $10^{-1} \mathrm{~Hz}$, and display low coherency above $0.1 \mathrm{~Hz}$. These results clearly illustrate that the Nafion dryer is very effective at reducing the high-frequency contributions of the water vapor measurements. By using the integral of the cospectrum we found that the water vapor flux was reduced by $97 \%$.

It is imperative that the attenuation of fast fluctuations as observed in the water vapor signal is not seen in the ozone signal, as this would alter the ozone flux determination. Figure $7 \mathrm{~b}$ shows the power spectra of the ozone signal with and without the Nafion dryer installed in the sampling flow path. The ozone signal has a relatively large contribution from lower frequencies in the $<0.1 \mathrm{~Hz}$ range. The inertial subrange is between 0.1 and $0.7 \mathrm{~Hz}$. White noise is seen at frequencies higher than $0.7 \mathrm{~Hz}$. The spectral components of the ozone signal remained unchanged when using the Nafion dryer, which confirms earlier results presented in this manuscript showing that there is not an attenuation of the ozone signal by the Nafion dryer. A slight increase of the signal is apparent in the white noise frequencies greater than $0.7 \mathrm{~Hz}$. This increase was observed in other time periods examined and can be explained by the additional tubing required for the Nafion dryer causing a slight loss in the fast frequencies of the ozone signal. These results give confidence in the possibility of using a Nafion drying system when measuring ozone surface fluxes.

\subsection{Inlet filter test}

In order to prevent contamination of the sampling line from salt water sea spray, or other particulate matter, it has been a standard operating procedure to direct the sample air through a Teflon membrane in-line sampling filter. Filters used in our field measurements are conditioned prior to use by purging $\sim 300 \mathrm{nmol} \mathrm{mol}^{-1}$ of ozone through the filter for $\sim 15 \mathrm{~h}$ at a flow rate of $4 \mathrm{~L} \mathrm{~min}^{-1}$. Filters are typically changed daily on oceanic research cruises in order to minimize the buildup of particulate matter on the filter. The effects of the Teflon filter on both the ozone and water vapor signal were investigated in the controlled laboratory setting. The filter was inserted into the setup directly downstream of the tee where the humidified 
and ozone-enriched air flows were mixed together. Ozone and water vapor were held constant at $\sim 100 \mathrm{nmol} \mathrm{mol}^{-1}$ and $26 \mathrm{mmol} \mathrm{mol}^{-1}$, respectively. The difference in the signal with and without the filter was less than $0.04 \mathrm{nmol} \mathrm{mol}^{-1}$ for ozone and $0.06 \mathrm{mmol} \mathrm{mol}^{-1}$ for water vapor. These differences were within the sampling noise of their respective instrument. There was no significant difference in absolute water vapor or ozone mole fractions and fast fluctuations with and without the filter installed.

\section{Summary and conclusions}

This investigation confirmed previously reported signal loss in an $\mathrm{O}_{3}$-NO chemiluminescence instrument due to the presence of atmospheric water vapor. The quenching effect of water vapor resulted in a loss of up to $11 \%$ in the ozone signal as measured by the FROI. A correction factor, $\alpha$, according to Eq. (1), was calculated to be $4.15 \times 10^{-3}$ for our system, which is of a similar magnitude as results from previous researchers despite differences in instrument configurations, sample and reactant flows, and data acquisition rates. We also demonstrated the effectiveness of a Nafion drying system to reduce the quenching effect of water vapor on the chemiluminescence signal. This was accomplished by a series of laboratory and outside ambient-air experiments. The installation of a Nafion drying system significantly reduced the amount of water vapor in the sample air. The fraction of water vapor removed by the dryer was nonlinear, increasing from $\sim 50 \%$ at $6 \mathrm{mmol} \mathrm{mol}^{-1}$ of water vapor to over $70 \%$ above $18 \mathrm{mmol} \mathrm{mol}^{-1}$ of water vapor. The drying efficiency was found to depend on the operating conditions of the dryer, increasing with dryer length and drying flow rate. The removal of water vapor molecules by the Nafion dryer results in an ozone enrichment upwards of $2 \%$. Most importantly, the Nafion dryer was found to be effective at attenuating the fast fluctuations of the water vapor signal. The ozone mean concentration and ozone fast fluctuations were not affected by the Nafion dryer. Consequently, the Nafion dryer is an efficient means of eliminating the interference from the water vapor flux and for reducing the density correction in the eddy covariance ozone flux measurement.
The same detection principle is used for atmospheric measurements of NO. In those chemiluminescence instruments, the air sample is mixed with a flow of ozone in air or ozone in oxygen as the reactant gas. While the ratio of reactant-gas flow to the sample flow is higher (than in instruments for the measurement of ozone, i.e. on the order of $1: 10$ compared to $1: 100$ for the measurement of ozone), the humidity content in the reaction chamber is still primarily determined by the sample flow. Consequently, these NO detection instruments suffer from a similar interference. To the best of our knowledge, researchers apply the same quenching correction coefficient in this instrument configuration, and we are not aware of targeted tests that have examined the quenching behavior in the NO measurement. In the NO measurement, calibrations can be performed by standard addition of a small flow of a NO calibration gas standard, which allows determining the actual instrument sensitivity at varying humidity for measurements of the NO mole fraction in ambient air. However, this approach does not compensate for the quenching interference of the fast water signal in the eddy covariance flux measurement of NO fluxes. Consequently, our study should be of interest for NO flux research as well. In particular, our findings suggest that inclusion of a Nafion dryer in the sample flow path will likely mitigate the fast quenching interference for the NO signal, and should likely yield an improvement in the determination of the NO flux by the eddy covariance technique.

Acknowledgements. We thank C. Fairall, K. Lang, and L. Bariteau for conducting and providing data for the ambient water vapor and ozone flux experiments.

Edited by: A. Hofzumahaus 


\section{Appendix A}

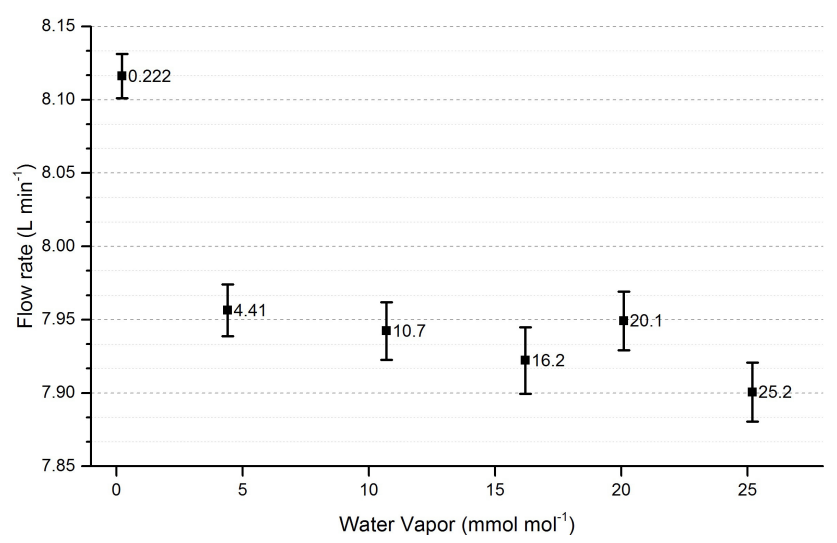

Fig. A1. Flow rate determined with a bubble meter, corrected for ambient pressure and temperature, against water vapor mole fraction for MFC 3 (Tylan FC-2900) operated at a constant flow rate set point. Each point shows the mean flow rate and the error bars represent the standard error with a sample size of 20. The numbers to the right of each point correspond to the water vapor content determined with the LI-7000.

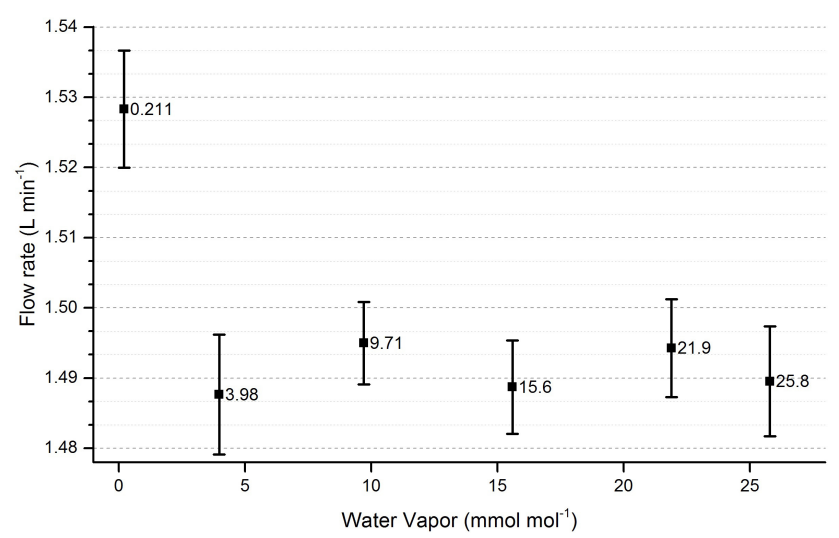

Fig. A2. Flow rate determined with the bubble meter, corrected for ambient pressure and temperature, against water vapor mole fraction for MFC 5 (Tylan FC-260) operated at a constant flow rate set point. Each point shows the mean flow rate and the error bars represent the standard error with a sample size of 20 . The numbers to the right of each point correspond to the water vapor content determined with the LI-7000.
Table A1. Averaged loss of ozone signal at the three different ozone levels tested $(30,60$, and $100 \mathrm{ppbv})$ as a function of the water vapor mixing ratio.

\begin{tabular}{lr}
\hline $\begin{array}{l}\mathrm{H}_{2} \mathrm{O} \\
\left(\mathrm{mmol} \mathrm{mol}^{-1}\right)\end{array}$ & $\begin{array}{r}\text { Average ozone signal loss } \\
\pm \text { standard deviation }\end{array}$ \\
\hline 6.2 & $2.5 \pm 0.2 \%$ \\
12.0 & $4.7 \pm 0.4 \%$ \\
17.9 & $7.1 \pm 0.7 \%$ \\
23.0 & $9.2 \pm 0.6 \%$ \\
27.1 & $11.2 \pm 0.9 \%$ \\
\hline
\end{tabular}




\section{References}

Bariteau, L., Helmig, D., Fairall, C. W., Hare, J. E., Hueber, J., and Lang, E. K.: Determination of oceanic ozone deposition by shipborne eddy covariance flux measurements, Atmos. Meas. Tech., 3, 441-455, doi:10.5194/amt-3-441-2010, 2010.

Cros, B., Delon, C., Affre, C., Marion, T., Druilhet, A., Perros, P. E., and Lopez A.: Sources and sinks of ozone in savanna and forest areas during EXPRESSO: Airborne turbulent flux measurements, J. Geophys. Res.-Atmos., 105, 29347-29358, doi:10.1029/2000jd900451, 2000.

Edwards, J. M.: Oceanic latent heat fluxes: Consistency with the atmospheric hydrological and energy cycles and general circulation modeling, J. Geophys. Res.-Atmos., 112, doi:10.1029/2006jd007324, 2007.

Evangelisti, F., Baroncelli, A., Bonasoni, P., Giovanelli, G., and Ravegnani, F.: Differential optical absorption spectrometer for measurement of tropospheric pollutants, Appl. Opt., 34, 27372744, 1995.

Fontijn, A., Sabadell, A. J., and Ronco, R. J.: Homogeneous chemiluminescence measurement of nitric oxide with ozone - implications for continuous selective monitoring of gaseous air pollutants, Anal. Chem., 42, 575-579, doi:10.1021/ac60288a034, 1970 .

Ganzeveld, L., Helmig, D., Fairall, C. W., Hare, J., and Pozzer, A.: Atmosphere-ocean ozone exchange: A global modeling study of biogeochemical, atmospheric, and waterside turbulence dependencies, Global Biogeochem. Cy., 23, GB4021, doi:10.1029/2008gb003301, 2009.

Guesten, H. and Heinrich, G.: On-line measurements of ozone surface fluxes: Part I. Methodology and instrumeneation, Atmos. Environ., 30, 897-909, 1996.

Helmig, D., Cohen, L. D., Bocquet, F., Oltmans, S., Grachev, A., and Neff, W.: Spring and summertime diurnal surface ozone fluxes over the polar snow at Summit, Greenland, Geophys. Res. Lett., 36, L08809, doi:10.1029/2008gl036549, 2009.

Helmig, D., Boylan, P., Johnson, B., Oltmans, S., Fairall, C. W., Staebler, R., Weinheimer, A., Orlando, J., Knapp, D., Montzka, D., Flocke, F., Freiß, U., Sihler, H., and Shepson, P.: Ozone Dynamics and Snow-Atmosphere Exchanges During Ozone Depletion Events at Barrow, Alaska, J. Geophys. Res.-Atmos., 117, D20303, doi:10.1029/2012JD017531, 2012a.

Helmig, D., Lang, E. K., Bariteau, L., Boylan, P., Fairall, C. W., Ganzeveld, L., Hare, J. E., Hueber, J., and Pallandt, M.: Atmosphere-ocean ozone fluxes during the TexAQS 2006, STRATUS 2006, GOMECC 2007, GasEx 2008, and AMMA 2008 cruises, J. Geophys. Res.-Atmos., 117, D04305, doi:10.1029/2011jd015955, 2012 b.

Hönninger, G., von Friedeburg, C., and Platt, U.: Multi axis differential optical absorption spectroscopy (MAX-DOAS), Atmos. Chem. Phys., 4, 231-254, doi:10.5194/acp-4-231-2004, 2004.

Hsu, J.: Multiple Comparisons: Theory and Methods, Chapman and Hall/CRC, Boca Raton, USA, 1996.

Ibrom, A., Dellwik, E., Larsen, S. E., and Pilegaard, K.: On the use of the Webb-Pearman-Leuning theory for closed-path eddy correlation measurements, Tellus Ser. B, 59, 937-946, doi:10.1111/j.1600-0889.2007.00311.x, 2007.

Kawa, S. R. and Pearson, R.: Ozone budgets from the dynamics and chemistry of marine stratocumulus experiment, J. Geophys. Res., 94, 9809-9817, 1989.
Kleindienst, T. E., Hudgens, E. E., Smith, D. F., McElroy, F. F., and Bufalini, J. J.: Comparison of chemiluminescence and ultraviolet ozone monitor responses in the presence of humidity and photochemical pollutants, J. Air Waste Manage. Assoc., 43, 213-222, 1993.

Komhyr, W. D., Barnes, R. A., Brothers, G. B., Lathrop, J. A., and Opperman, D. P.: Electrochemical concentration cell ozonesonde performance evaluation during STOIC 1989, J. Geophys. Res., 100, 9231-9244, doi:10.1029/94JD02175, 1995.

Lang, K.: Ozone flux measurements during the Gulf of Mexico and East Coast Carbon Cruise 2007 (GOMECC), M.S. thesis, University of Potsdam, Potsdam, 88 pp., 2008.

Lenschow, D. H. and Raupach, M. R.: The attenuation of flucuations in scalar concentrations through sampling tubes, J. Geophys. Res., 96, 15259-15268, doi:10.1029/91JD01437, 1991.

Lenschow, D. H., Pearson, R., and Stankov, B. B.: Estimating the ozone budget in the boundary-layer by use of aircraft measurements of ozone eddy flux and mean concentration, J. Geophys. Res., 86, 7291-7297, doi:10.1029/JC086iC08p07291, 1981.

Lenschow, D. H., Pearson, R., and Stankov, B. B.: Measurements of ozone vertical flux to ocean and forest, J. Geophys. Res., 87, 8833-8837, 1982.

Matthews, R. D., Sawyer R. F., and Schefer R. W.: Interferences in chemiluminescence measurement of $\mathrm{NO}$ and $\mathrm{NO}_{2}$ emissions from combustion systems, Environ. Sci. Technol., 11, 10921096, doi:10.1021/es60135a005, 1977.

Muller, P.: The equations of oceanic motions, Cambridge University Press, Cambridge, UK, 2006.

Ridley, B. A. and Grahek, F. E.: A small, low flow, high-sensitivity reaction vessel for no chemiluminescence detectors, J. Atmos. Oceanic Technol., 7, 307-311, 1990.

Ridley, B. A., Grahek, F. E., and Walega, J. G.: A small, highsensitivity, medium-response ozone detector suitable for measurements from light aircraft, J. Atmos. Oceanic Technol., 9, 142-148, 1992.

Slusher, D. L., Neff, W. D., Kim, S., Huey, L. G., Wang, Y., Zeng, T., Tanner, D. J., Blake, D. R., Beyersdorf, A., Lefer, B. L., Crawford, J. H., Eisele, F. L., Mauldin, R. L., Kosciuch, E., Buhr, M. P., Wallace, H. W., and Davis, D. D.: Atmospheric chemistry results from the ANTCI 2005 Antarctic plateau airborne study, J. Geophys. Res., 115, D07304, doi:10.1029/2009JD012605, 2010.

Spicer, C. W., Joseph, D. W., and Ollison, W. M.: A Re-Examination of Ambient Air Ozone Monitor Interferences, J. Air Waste Manage. Assoc., 60, 1353-1364, doi:10.3155/1047-3289.60.11.1353, 2010.

Stull, R. B.: An introduction to boundary layer meteorology, Kluwer Academic Publishers, Dordrecht, The Netherlands, 1988.

Wang, C.: Thermal Mass Flow Controller Scaling Relations, Measurement Science Conference, Anaheim, CA, 22-23 March 2012, 2012.

Webb, E. K., Pearman, G. I., and Leuning, R.: Correction of flux measurements for density effects due to heat and water-vapor transfer, Q. J. R. Meteorol. Soc., 106, 85-100, doi:10.1002/qj.49710644707, 1980.

Weinheimer, A. J.: Chemical methods: chemiluminescence, chemical amplification, electrochemistry, and derivatization, in: Analytical techniques for atmospheric measurement, edited by: Heard, D. W., Blackwell Publishing, 2006. 
Weinheimer, A. J., Montzka, D. D., Campos, T. L., Walega, J. G., Ridley, B. A., Donnelly S. G., Keim, E. R., Del Negro, L. A., Proffitt, M. H., Margitan, J. J., Boering, K. A., Andrews, A. E., Daube, B. C., Wofsy, S. C., Anderson, B. E., Collins, J. E., Sachse, G. W., Vay, S. A., Elkins, J. W., Wamsley, P. R., Atlas, E. L., Flocke, F., Schauffler, S., Webster, C. R., May, R. D., Loewenstein, M., Podolske, J. R., Bui, T. P., Chan, K. R., Bowen, S. W., Schoeberl, M. R., Lait, L. R., and Newman, P. A.: Comparison between DC- 8 and ER-2 species measurements in the tropical middle troposphere: $\mathrm{NO}, \mathrm{NO}_{\mathrm{y}}, \mathrm{O}_{3}, \mathrm{CO}_{2}, \mathrm{CH}_{4}$, and $\mathrm{N}_{2} \mathrm{O}$, J. Geophys. Res., 103, 22087-22096, doi:10.1029/98JD01421, 1998.

Wesely, M. L. and Hicks B. B.: A review of the current status of knowledge on dry deposition, Atmos. Environ., 34, 2261-2282, 2000 .
Williams, E. J., Fehsenfeld, F. C., Jobson, B. T, Kuster, W. C., Goldan, P. D., Stutz, J., and McCleanny, W. A.: Comparison of ultraviolet absorbance, chemiluminescence, and DOAS instruments for ambient ozone monitoring, Environ. Sci. Technol., 40, 5755-5762, doi:10.1021/es0523542, 2006.

Wilson, K. L. and Birks, J. W.: Mechanism and elimination of a water vapor interference in the measurement of ozone by UV absorbance, Environ. Sci. Technol., 40, 6361-6367, doi:10.1021/es052590c, 2006.

Zahn, A., Weppner, J., Widmann, H., Schlote-Holubek, K., Burger, B., Kuhner, T., and Franke, H.: A fast and precise chemiluminescence ozone detector for eddy flux and airbore application, Atmos. Meas. Tech., 5, 363-375, doi:10.5194/amt-5-363-2012, 2012.

Zeller, K.: Wintertime ozone fluxes and profiles above a subalpine spruce-fir forest, J. Appl. Meteorol., 39, 92-101, 2000. 